\title{
Scant evidence for a volcanically forced winter warming over Eurasia following the Krakatau eruption of August 1883
}

\author{
Lorenzo M. Polvani ${ }^{1,2,3}$ and Suzana J. Camargo ${ }^{2,3}$ \\ ${ }^{1}$ Department of Applied Physics and Applied Mathematics, Columbia University, New York, NY 10027, USA \\ ${ }^{2}$ Department of Earth and Environmental Sciences, Columbia University, New York, NY 10027, USA \\ ${ }^{3}$ Lamont-Doherty Earth Observatory, Columbia University, Palisades, NY 10964, USA
}

Correspondence: Lorenzo M. Polvani (lmp@columbia.edu)

Received: 23 March 2020 - Discussion started: 22 June 2020

Revised: 17 September 2020 - Accepted: 3 October 2020 - Published: 14 November 2020

\begin{abstract}
A recent study has presented compelling new evidence suggesting that the observed Eurasian warming in the winter following the 1992 Pinatubo eruption was, in all likelihood, unrelated to the presence of volcanic aerosols in the stratosphere. Building on that study, we turn our attention to the only other low-latitude eruption in the instrumental period with a comparably large magnitude: the Krakatau eruption of August 1883. We study the temperature anomalies in the first winter following that eruption in detail, analyzing (1) observations, (2) reanalyses, and (3) models. Three findings emerge from our analysis. First, the observed postKrakatau winter warming over Eurasia was unremarkable (only between $1 \sigma$ and $2 \sigma$ of the distribution from 1850 to present). Second, reanalyses based on assimilating surface pressure alone indicate the existence of very large uncertainties, so much so that a Eurasian cooling is not incompatible with those reanalyses. Third, models robustly show the complete absence of a volcanically forced Eurasian winter warming: here, we analyze both a 100-member initial-condition ensemble and 140 simulations from Phase 5 of the Coupled Model Intercomparison Project. This wealth of evidence strongly suggests that, as in the case of Pinatubo, the observed warming over Eurasia in the winter of 1883-84 was, in all likelihood, unrelated to the Krakatau eruption. This, taken together with a similar result for Pinatubo, leads us to conclude that if volcanically forced Eurasian winter warming exists at all, an eruption with a magnitude far exceeding these two events would be needed to produce a detectable surface warming.
\end{abstract}

\section{Introduction}

The vexed question of whether large, low-latitude volcanic eruptions are able to cause a winter warming of the continents in the Northern Hemisphere is receiving renewed attention. As the extant literature is quite confusing and often contradictory, a brief summary of how this topic has evolved will help set the stage for the present study.

The surprising idea of a post-eruption warming, obviously at odds with the naive expectation of a surface cooling from additional reflection of incoming short-wave radiation by the volcanic aerosols, was championed by a series of early observational studies (Groisman, 1992; Robock and Mao, 1992, 1995). These were accompanied by modeling studies (Graf et al., 1993; Kirchner et al., 1999) which reported a causal relationship between strong eruptions and a positive phase of the North Atlantic Oscillation (NAO) in winter. These early studies were highly influential because they proposed a cogent physical mechanism linking low-latitude eruptions to high-latitude surface temperatures anomalies. In a nutshell, the lower stratospheric tropical warming associated with the absorption of long-wave radiation by the volcanic aerosols increases the Equator-to-pole stratospheric temperature gradients, resulting in an anomalously strong polar vortex leading, in turn, to a positive NAO phase and eventually a surface warming over Eurasia in the winter months (Kodera, 1994; Perlwitz and Graf, 1995). We will refer to this mechanism as the "stratospheric pathway".

While such a mechanism appears plausible, these early observational and modeling claims have not stood the test of time. For instance, analyzing 15 eruptions in one temper- 
ature reconstruction extending back to 1586 , Fischer et al. (2007) found that the largest winter warming over Europe seems to occur in the second post-eruption winter, not the first. If confirmed by other reconstructions, this result would obviously negate the stratospheric pathway mechanism, as the amount of aerosol left in stratosphere in the second posteruption winter is a small fraction of the amount present in the first winter, and no physical process has been proposed that would provide a multiyear-long memory in the polar stratosphere and the NAO. Even more perplexing are the numerous studies (e.g., Thomas et al., 2009a; Driscoll et al., 2012; Toohey et al., 2014; Bittner, 2015; Wunderlich and Mitchell, 2017, just to cite the most recent papers), which have analyzed dozens of state-of-the art climate remodels and repeatedly failed to replicate the early modeling results. Averaging over many different low-latitude eruptions, over many models, and over many runs, these more recent studies have consistently reported the lack of a statistically significant post-eruption surface winter warming over Eurasia. This begs the question: how could the later, better models fail to simulate the causal connection reported with the earlier, simpler models?

A resolution to this conundrum was recently proposed by Polvani et al. (2019), hereafter PBS19, who showed that much of the earlier literature had failed to properly account for the large internal variability associated with the stratospheric polar vortex and with the NAO. Focusing primarily on the 1991 Pinatubo eruption, PBS19 analyzed three "large ensembles" of model runs, and showed how tiny initial perturbations of the same model forced with the same volcanic aerosols result in vastly different winter temperature anomalies over Eurasia. They also showed that, averaging over many runs, i.e., computing the "forced" response, yields insignificant post-eruption anomalies, in agreement with most recent studies. The early modeling studies, it so happens, simply lacked the vertical and horizontal resolution to properly simulate the internal variability of the Northern Hemisphere circulation and, thus, yielded spurious results. Therefore, PBS19 concluded that the observed Eurasian surface warming in the winter of 1991-92 was, very likely, not caused by the preceding eruption of Mt. Pinatubo.

That conclusion appears unassailable, as PBS19 merely corroborated the lack of a forced post-eruption winter warming already reported by many previous studies with many other models. Nonetheless, one might argue that the 1991 Pinatubo eruption was somehow peculiar and, thus, unrepresentative of most, large, low-latitude eruptions. To determine if this is so different eruptions need to be examined. PBS19 did, in fact, examine the 1982 El Chichón eruption (Robock, 1983) with the same three large ensembles, and they again concluded that the winter warming over Eurasia in the winter of 1982-83 was, in all likelihood, unrelated to El Chichón. This is perhaps unsurprising, as the El Chichón eruption was of a smaller magnitude than the Pinatubo eruption. What is really needed, it should be clear, is a low-latitude eruption at least comparable in magnitude, if not larger, than the last Pinatubo eruption.

Hence, building on PBS19, in this study we examine the eruption of Mt. Krakatau in August of 1883. There are several reasons for focusing on that eruption. First, it is the only low-latitude eruption that occurred during the instrumental period with a magnitude comparable to the 1991 Pinatubo eruption (Robock, 2000), with respect to both the volcanic explosivity index (VEI) and the dust veil index $(\mathrm{DVI}=1000)$ : this means that we can establish, with some confidence, whether Eurasia was anomalously warm or cold in the first winter after the eruption. Second, the Twentieth Century Reanalysis (Compo et al., 2006) starts in 1851 and, thus, includes that eruption. In fact, not a single reanalysis, but a 56-member ensemble of that reanalysis is now available, so that the observational uncertainties can be quantified. Third, the historical integrations of dozens of models participating in Phase 5 of the Coupled Model Intercomparison Project (hereafter CMIP5; Taylor et al., 2012) also start at 1850: there is, therefore, a wealth of model output that covers that eruption, and we will examine both a large initial condition ensemble (100 members) and the multi-model CMIP5 ensemble.

As we will show in detail below, this wealth of data allows us to establish three facts: (1) Eurasia was indeed warmer than average in the winter following the 1883 eruption of Mt. Krakatau, but (2) the anomalous warming that winter was in no way exceptional, and (3) it is unlikely that volcanic aerosols were the cause of, or even substantially contributed to, that warming. After a brief section on methods, each of these facts will be discussed in detail in Sects. 3-5. The paper will close with a summary and discussion.

\section{Methods}

\subsection{Definitions}

For each of the datasets detailed in the following subsection, we quantify the potential impact of the 1883 Krakatau eruption by computing a winter temperature anomaly, defined as the difference between the surface temperature in the winter of 1883-84 (i.e., the average of December 1883, January 1884 , and February 1884) and the mean over a reference period, chosen to be five previous winters (i.e., from 1878-89 to 1882-83). For brevity, we will sometime refer to this quantity as "the post-Krakatau anomaly" or simply "the anomaly." Unless otherwise stated, the length of five seasons is chosen for the reference period throughout this paper; this is done to remain consistent with PBS19, so that the post-Krakatau anomalies may be quantitatively ${ }^{1}$ compared with the post-

\footnotetext{
${ }^{1}$ Stenchikov et al. (2006), Driscoll et al. (2012), Bittner et al. (2016a), and most other studies opted to use reference periods of different lengths for different eruptions. We understand their motivation for doing so: compositing the longest possible number of un-
} 
Pinatubo anomalies. In the figures, we will use $\Delta T_{\mathrm{S}}$ to refer to these temperature anomalies.

Furthermore, as explained in detail in PBS19 and also suggested by Zambri and Robock (2016) and Bittner et al. (2016a), there is no plausible reason to consider the second winter after the eruption, as no study to date has proposed a credible mechanism that would allow anomalies caused by the volcanic aerosols to affect the stratospheric polar vortex and the NAO beyond the first winter. Finally, to compute time series and probability distribution functions, the average Eurasian anomaly is computed as the mean over the region from 40 to $70^{\circ} \mathrm{N}$ and from 0 to $150^{\circ} \mathrm{W}$, as in PBS19. We will refer to this as the "Eurasian box." Our results are insensitive to this choice, as one can see from the actual anomaly maps, shown throughout the paper.

\subsection{Datasets}

To construct a comprehensive and convincing picture of the potential impact of the 1883 Krakatau eruption on wintertime Eurasian temperatures, we analyze three different types of surface temperature data here: observational reconstructions, reanalyses, and model output. We describe each one in detail in the following subsections.

\subsubsection{Observations}

Here, three distinct datasets that have constructed observational estimates of monthly averaged temperatures are analyzed:

1. the NOAA merged Global Surface Temperature (NOAAGlobalTemp) dataset, version 4.00, spanning the period from January 1880 to present (Smith et al., 2008; Vose et al., 2012) - we will refer to this as the NOAA anomalies;

2. the GISS Surface Temperature Analysis, version 4, spanning the period from January 1880 to present (Lenssen et al., 2019) - we will refer to this as the GISTEMP anomalies;

3. the Climate Research Unit (CRU) air temperature anomalies, version 4, spanning the period from January 1850 to present (Jones et al., 2012) - we will refer to this as the CRUTEM anomalies.

While all three cover the 1883 Krakatau eruption, both the NOAA and GISTEMP products start at 1880 , so only three winters are available to define a pre-eruption reference period. We test the robustness of the estimated anomalies as a function of the reference period in Sect. 3 below.

perturbed years prior to each eruption. Our goal, however, is a little different: we are trying to validate the Pinatubo findings of PBS19 with a different eruption. Hence, we prefer to use the same reference period as PBS19, to avoid introducing a source of potential confusion. In any case, we show below that the results are largely insensitive to the length of the reference period.

\subsubsection{Reanalyses}

At the time of writing, the majority of available reanalyses reach back to 1979, the start of the satellite era, or a little earlier (e.g., JRA-55, Kobayashi et al., 2015, which starts at 1958), with only a few extending back to the beginning of the 20th century (e.g., ERA-20C; Poli et al., 2016): unfortunately, none of these serve our purposes. However, the NOAA-CIRES Twentieth Century Reanalysis, version $2 \mathrm{c}$ (hereafter 20CR; Compo et al., 2011) extends back to January 1851 and can, thus, be used to study the 1883 Krakatau eruption. Recall that $20 \mathrm{CR}$ only assimilates sea level pressure measurements (Compo et al., 2006), while the underlying atmospheric model is forced with sea surface temperature reconstructions (Rayner et al., 2003) and time varying $\mathrm{CO}_{2}$ concentrations, incoming solar radiation, and volcanic aerosols. More importantly here, we analyze a 56-member ensemble of 20CR: this allows us to quantify the uncertainties associated with the post-eruption Eurasian temperature anomalies.

\subsubsection{Models}

It so happens that a huge amount of model output is available to study the 1883 Krakatau eruption. To a large degree, this is due to the fact that the CMIP5 project recommended that all so-called "historical" integrations should be initialized at the year 1850. Over that period, the CMIP5 also specified how models ought to be forced, with both natural (i.e., solar and volcanic) and anthropogenic (e.g., $\mathrm{CO}_{2}$ ) forcings, in order be directly comparable with observations. Specifically, we analyze two distinct datasets here.

1. First, we consider the 100 -member ensemble of historical simulations called the "MPI Grand Ensemble", produced by the Max Planck Institute for Meteorology (hereafter MPI; Maher et al., 2019). The atmospheric component of that model (MPI-ESM-LR) has a horizontal resolution of approximately $1.9^{\circ}$ (at the Equator) and 47 vertical levels with a model top at $0.01 \mathrm{hPa}$. As such, it is a so-called "high-top" model, with a good representation of the stratospheric circulation and, more importantly, of its variability. We note, in passing, that the other widely analyzed large ensemble (Kay et al., 2015) was initialized at the year 1920 and, therefore, cannot be used for the purposes of this study. All simulations in this ensemble are performed with an identical model configuration and with identical forcings, following the CMIP5 protocol: they only differ in their initial conditions. This ensemble of runs allows us to unambiguously quantify the importance of internal variability and contrast it with the forced response.

2. Next, we consider the CMIP5 historical (1850-2005) integrations: the output of 40 distinct models is available, with many groups contributing small ensembles 
Table 1. Acronym, number of simulations, and high-top/low-top classification (based on Rea et al., 2018) for the historical integrations of the CMIP5 models analyzed in this paper. Information on model forcings and experimental design can be found in Taylor et al. (2012).

\begin{tabular}{lrl|lrl}
\hline Model name & Members & Type & Model name & Members & Type \\
\hline ACCESS1.0 & 1 & LT & GISS-E2-H-CC & 1 & HT \\
ACCESS1.3 & 1 & LT & GISS-E2-R & 16 & HT \\
bcc-csm1-1 & 3 & LT & GISS-E2-R-CC & 1 & HT \\
bcc-csm1-1-m & 3 & LT & HadCM3 & 10 & LT \\
BNU-ESM & 1 & LT & HadGEM2-CC & 1 & HT \\
CCSM4 & 6 & LT & HadGEM2-ES & 4 & LT \\
CESM1-BGC & 1 & LT & inmcm4 & 1 & LT \\
CESM1-CAM5 & 3 & LT & IPSL-CM5A-LR & 5 & HT \\
CESM1-FASTCHEM & 3 & LT & IPSL-CM5A-MR & 3 & HT \\
CESM1-WACCM & 1 & HT & IPSL-CM5B-LR & 1 & HT \\
CMCC-CESM & 1 & HT & MIROC-ESM & 3 & HT \\
CMCC-CM & 1 & LT & MIROC-ESM-CHEM & 1 & HT \\
CMCC-CMS & 1 & HT & MIROC5 & 5 & LT \\
CNRM-CM5 & 10 & LT & MPI-ESM-LR & 3 & HT \\
CSIRO-Mk3-6-0 & 10 & LT & MPI-ESM-MR & 3 & HT \\
FGOALS-g2 & 4 & LT & MPI-ESM-P & 2 & HT \\
FIO-ESM & 3 & LT & MRI-CGCM3 & 5 & HT \\
GFDL-CM3 & 5 & HT & MRI-ESM1 & 1 & HT \\
GFDL-ESM2G & 3 & LT & NorESM1-M & 3 & LT \\
GISS-E2-H & 10 & HT & NorESM1-ME & 1 & LT \\
\hline
\end{tabular}

of runs (typically 3-10 members), for a total of 140 historical runs. The specific models analyzed here and the number of integrations available are listed in Table 1 . We examine all available simulations from these models, sorting the models into two categories - hightop models and low-top models - following the classification in Charlton-Perez et al. (2013) and Rea et al. (2018). If, as argued in the early studies, the stratospheric pathway is indeed operative, one should be able to see a clear difference between the models with a good representation of the stratosphere and those with a poorer representation.

\section{Observations}

We start by determining whether, in the first winter after the Krakatau eruption of August 1883, Eurasia was anomalously warm or anomalously cold. It is important to stress that for most eruptions occurring before the 19th century, not only is the strength of the eruption difficult to estimate, but even the surface temperature anomalies over Eurasia are only known with considerable uncertainties, as those eruptions predate the instrumental period. Hence, the 1883 Krakatau eruption offers the only opportunity - other than the 1991 Pinatubo eruption - to examine a large, low-latitude event for which the surface temperature anomalies can be determined robustly.

The post-Krakatau wintertime anomalies for the CRUTEM dataset are illustrated in Fig. 1a-c. Focusing first on Fig. 1b, where the December to February (DJF) mean is shown, we see a clear warming of the Eurasian continent. This independently confirms the results shown in Fig. 1 of Robock and Mao (1992) and again in Fig. 1 of Shindell et al. (2004), which were obtained with an earlier version of the CRU temperature reconstruction and with slightly different methodologies. The post-Krakatau warming in DJF is further corroborated by the other two reconstructions that we have analyzed, the NOAA and GISTEMP datasets, shown in Fig. 1e and f, respectively. Note, however, that the reference period for those two datasets is shorter (only three winters) than the standard five-winter period used throughout this paper, as those reconstructions do not extend far enough into the past.

One might then legitimately wonder about the degree to which these anomalies might depend on the length of the reference period used. To address that concern, in Fig. 2 we show the post-Krakatau anomalies computed with respect to a 3-, 5-, and 10-winter reference period from the CRUTEM product, which is the only product for which this calculation can be performed. As one can see, the warming in DJF is very robust: averaged over the Eurasian box, we obtain a mean warming of $1.75,1.89$, and $1.91^{\circ} \mathrm{C}$ for $3-, 5-\mathrm{m}$, and 10 -winter reference periods, respectively. Therefore, we conclude that the post-Krakatau DJF temperature anomaly is robust in the observations, irrespective of the dataset and reference period one uses.

Having established that a relative warming over Eurasia did, in fact, occur in the first winter following the 1883 Krakatau eruption, we now ask two important questions: 
(a) CRUTEM NDJ

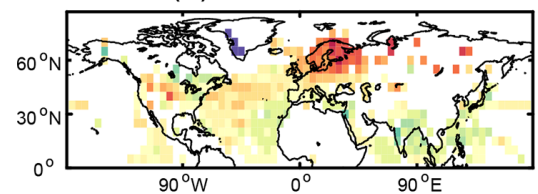

(d) GISTEMP NDJ

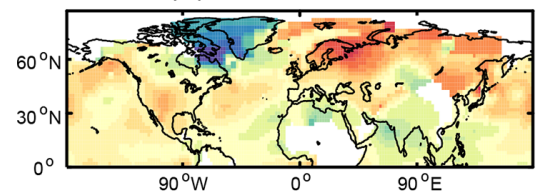

(g) NOAA NDJ

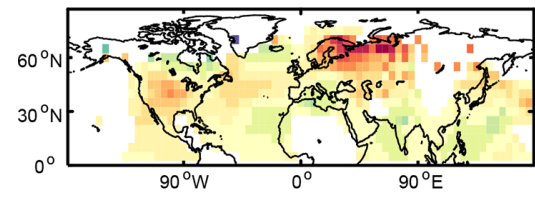

(b) CRUTEM DJF

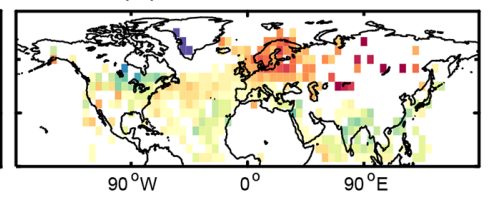

(e) GISTEMP DJF

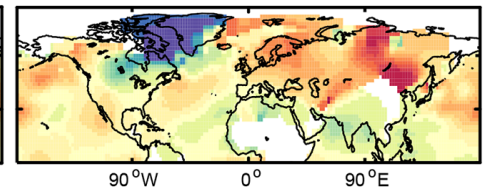

(h) NOAA DJF

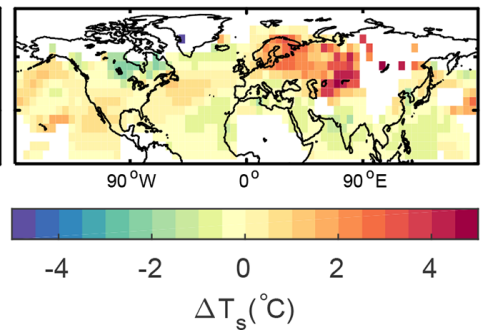

(c) CRUTEM JFM

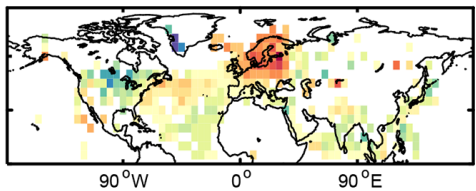

(f) GISTEMP JFM

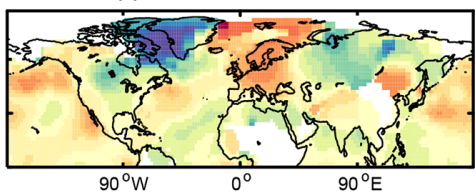

(i) NOAA JFM

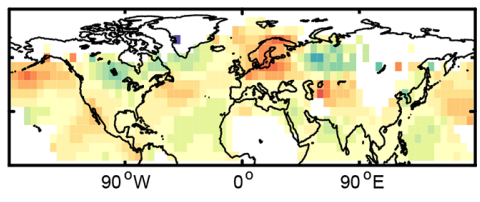

Figure 1. (a-c) CRUTEM post-Krakatau surface temperature anomalies $\left(\Delta T_{\mathrm{S}}\right)$ averaged over (a) November to January, (b) December to February, and (c) January to March. Panels (d-f) and panels $(\mathbf{g}-\mathbf{i})$ are the same as panels $(\mathbf{a}-\mathbf{c})$ but for GISTEMP and NOAA, respectively. Due to data availability, the anomalies panels $(\mathbf{d}-\mathbf{f})$ and panels $(\mathbf{g}-\mathbf{i})$ are computed using a shorter three-winter reference period.

\section{How persistent was this anomaly}

\section{How unusual was it?}

To shed some light on the persistence, we have plotted the November to January (NDJ) and January to March (JFM) anomalies in Fig. 1a, d, and g and in Fig. 1c, f, and i, respectively. While Eurasian warming is present in NDJ, one can see that it turns into a cooling in JFM, notably to the east of the Ural Mountains. Examination of individual months (not shown) reveal a clear cooling over the Urals starting in February and becoming large enough in March to dominate the JFM average. This suggests that, at least for this event, the warming anomalies over Eurasia did not persist into the late winter. Note that the seasonal polar vortex breakdown typically occurs around 15 April (as estimated from reanalyses, over the 1981-2016 period, by Butler et al., 2019): hence, the presumed stratospheric pathway would be operative in the month of March, but it does not appear to be persistent.

Finally, focusing again on the DJF months, we address the question of whether the post-Krakatau winter warming anomalies over Eurasia were, in some way, exceptional. Recall that the 1883 eruption of Mt. Krakatau was a cataclysmic event, causing over 36000 deaths and producing a global cooling that lasted for several years, with temperatures not returning to normal until 1888 (Simkin and Fiske, 1983). Two modeling studies have even claimed that Krakatau may have so strongly impacted Southern Ocean temperatures as to alter ocean heat uptake for many decades (Fyfe, 2006; Gleckler et al., 2006). In such a context, one might expect the 1883-84 Eurasian temperature anomalies to clearly stand out.

It is perhaps disappointing, therefore, to discover that the post-Krakatau anomalies are far from exceptional, when compared to those from all of the winters available in the instrumental record, as shown in Fig. 3a. In that figure, we plot the probability distribution function (PDF) of wintertime (DJF) anomalies averaged over the Eurasian box, computed using all the available winters in the CRUTEM datasets (from 1850 to present), with the post-Krakatau winter highlighted by the blue vertical line. Notice how that line falls almost evenly between the $1 \sigma$ and $2 \sigma$ (dashed) lines: with a mean value at $1.89^{\circ} \mathrm{C}$, the winter of $1883-84$ falls within the 85 th percentile of the distribution. This is confirmed by the PDFs computed from the NOAA and GISTEMP datasets, using the shorter three-winter reference period, shown in Fig. $3 \mathrm{~b}$ and c, respectively. In those datasets, the anomalies also fall between $1 \sigma$ and $2 \sigma$ of the PDF. Thus, while the months (and years) following the 1883 Krakatau eruption may have been memorable in many respects, that adjective does not apply to the Eurasian wintertime anomalies. We emphasize that this result does not rely on the use of any climate models: it is a purely observational result, and it is robust across the three temperature reconstructions analyzed here. 
(a) 3 winters

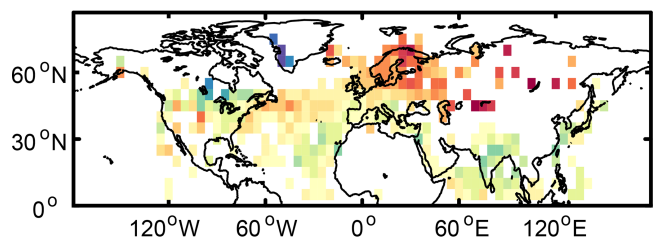

(b) 5 winters

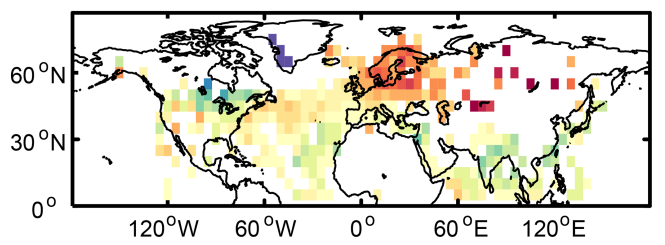

(c) 10 winters

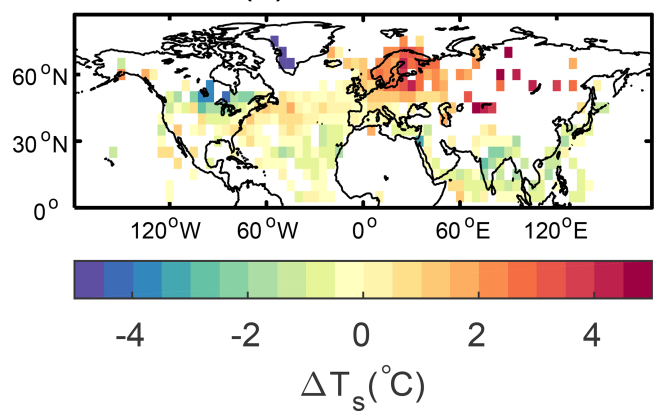

Figure 2. Post-Krakatau CRUTEM surface temperature anomalies $\left(\Delta T_{\mathrm{S}}\right)$ in DJF, using (a) 3, (b) 5, and (c) 10 winters for the reference period.

\section{Reanalyses}

Next we turn to examining the 20CR reanalysis, for which a 56-member ensemble is available, starting from the year 1850. Figure $4 \mathrm{a}-\mathrm{c}$ shows the ensemble mean post-Krakatau Eurasian anomalies in 20CR, for NDJ, DJF, and JFM, and can be directly compared with Fig. 1a-c. Although only sea level pressure measurements are assimilated into 20CR, its temperature anomalies are in good agreement with the observations. Note, in particular, how warming in NDJ and DJF gives way to a cooling in JFM over a large portion of Eurasia. This good agreement is perhaps not surprising, as an accurate reanalysis is expected to capture the observations.

Surprising, perhaps, is what can be seen by examining individual members of the ensemble. The anomalies for member no. 42 are shown in Fig. 4d-f: this is the member with the minimum temperature anomalies in DJF across the ensemble. Note the strong cooling in NDJ and DJF over most of Eurasia, which is diametrically opposite to the ensemble mean. It is important to stress that member no. 42 is driven by the same natural and anthropogenic forcings (including volcanic aerosols and $\mathrm{CO}_{2}$ ) and is constrained by the same sea level pressure measurements as all of the other members

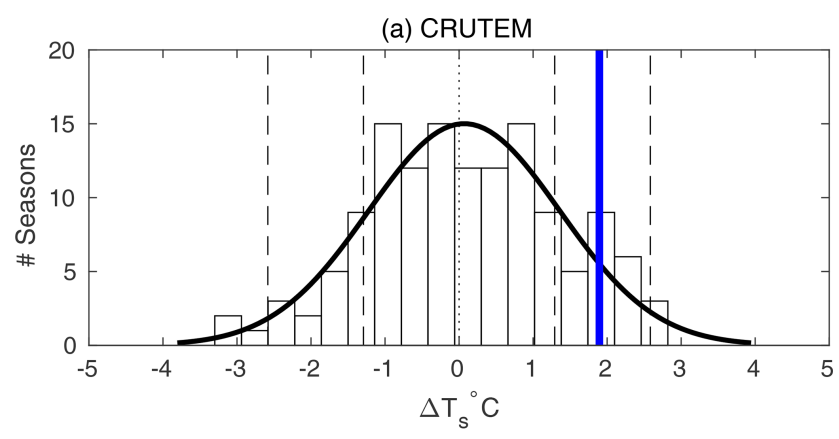

(b) GISTEMP

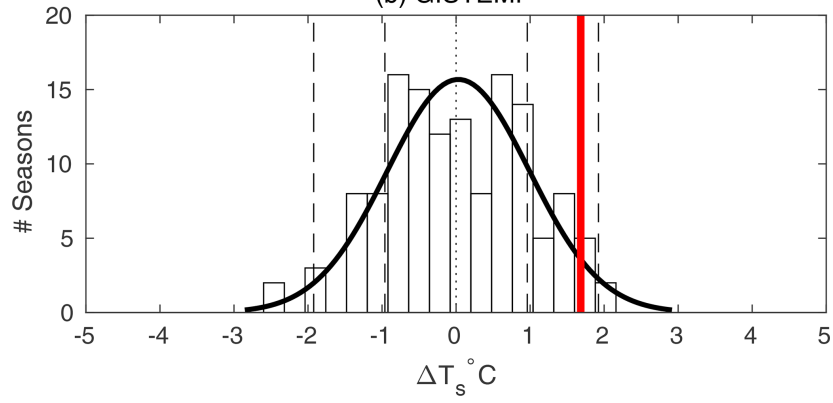

(c) NOAA

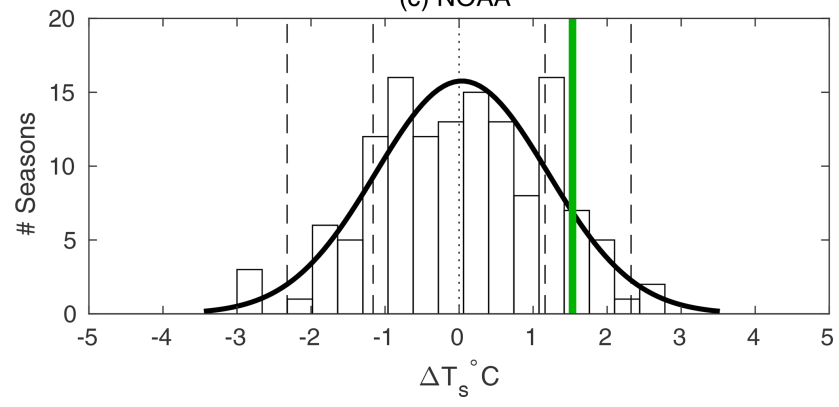

Figure 3. (a) The black boxes show the histogram of the CRUTEM post-Krakatau Eurasian temperature anomalies $\left(\Delta T_{\mathrm{S}}\right)$ in DJF, over the period from 1850 to present. The colored bar shows the 1883-84 post-Krakatau anomalies, the solid black lines represent a Gaussian fit, and dashed black lines show the $1 \sigma$ and $2 \sigma$ intervals. Panels (b) and (c) are the same as panel (a) but for GISTEMP and NOAA, respectively, using the shorter three-winter reference period.

of the ensemble. Therefore, its Eurasian cooling anomalies are entirely consistent with those forcings and observations.

For completeness, we show the member with the maximum Eurasian temperature anomalies in DJF (member no. 7) in Fig. $4 \mathrm{~g}-\mathrm{i}$. The contrast with member no. 42 is remarkable. The key point here is that, driven with identical forcings and observations, these two members give diametrically opposite results. The conclusion, therefore, is that the observational uncertainties are large and that, while its occurrence is unlikely (only 3 of 56 members), a post-Krakatau cooling over Eurasian is not incompatible with the $20 \mathrm{CR}$ reanalysis. 
(a) NDJ Ens. Mean

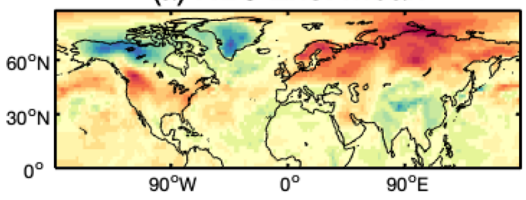

(d) NDJ \#42

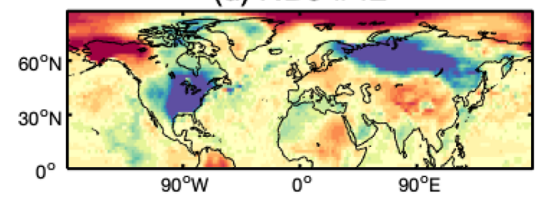

(g) NDJ \#7

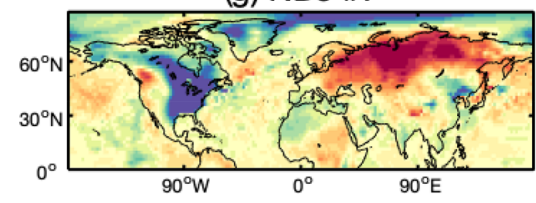

(b) DJF Ens. Mean

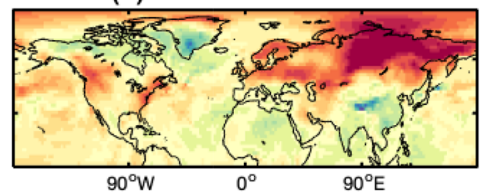

(e) DJF \#42

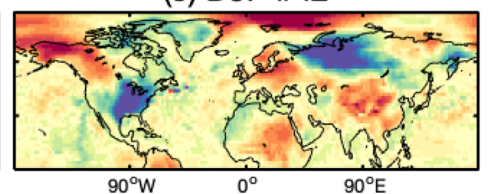

(h) DJF \#7

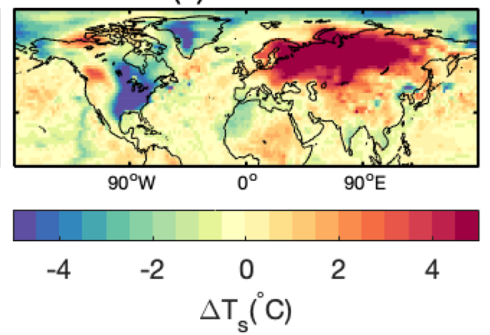

(c) JFM Ens. Mean

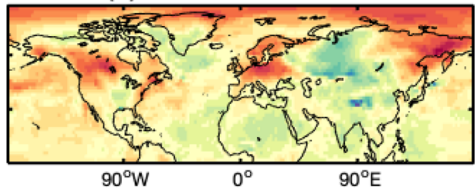

(f) JFM \#42

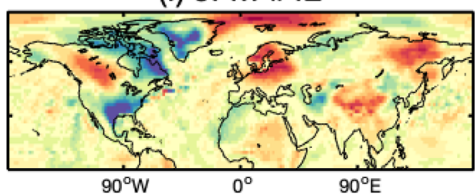

(i) JFM \#7

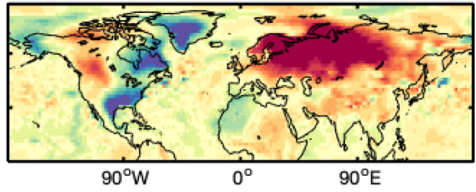

Figure 4. (a-c) 20CR ensemble mean, post-Krakatau, surface temperature anomalies $\left(\Delta T_{\mathrm{S}}\right)$ averaged over (a) November to January, (b) December to February, and (c) January to March. Panels (d-f) are the same as panels (a-c) but for ensemble member no. 42. Panels $(\mathbf{g}-\mathbf{i})$ are the same as panels (a-c) but for ensemble member no. 7. Member nos. 42 and 7 have the respective minimum and maximum post-Krakatau Eurasian DJF anomalies across the 56-member 20CR ensemble.

\section{Models}

Finally, to quantify the volcanically forced post-Krakatau Eurasian wintertime surface temperature anomaly (if any), i.e., to separate it from the large internal variability, and to establish whether the stratospheric pathway mechanism may have been operative in the first winter following that eruption, we turn to climate models. We start by examining the 100-member ensemble of historical simulations made available by the Max Plank Institute for Meteorology (hereafter MPI; Maher et al., 2019). We are aware that several large, initial-condition ensembles of historical simulations are now available (Deser et al., 2020). Here, we have chosen to focus on the MPI ensemble for two reasons: first, with $100 \mathrm{mem}-$ bers, it is the largest ensemble currently available; second, the atmospheric component is a so-called "high-top" model, with a good representation of the stratospheric circulation and, more importantly, of its variability. This is important if one is trying to evaluate whether the stratospheric pathway mechanism is indeed affecting the post-eruption Eurasian winter surface temperatures.

We start by examining the tropical, lower-stratospheric, post-eruption, temperature anomalies in the historical MPI simulations, to ensure that the volcanic aerosols in that model do indeed produce a noticeable warming in that region after each large, low-latitude eruption. The time series of tropical $50 \mathrm{hPa}$ temperature anomalies, from 1850 to 2015, are shown in Fig. 5. Comparison with Fig. 3 of Driscoll et al.

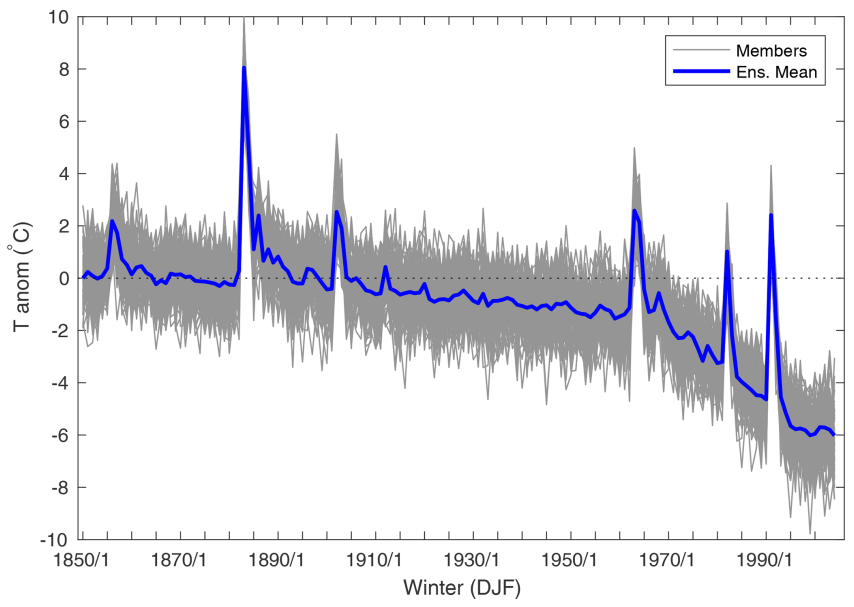

Figure 5. Tropical $\left(30^{\circ} \mathrm{S}-30^{\circ} \mathrm{N}\right)$ temperature anomalies in DJF at $50 \mathrm{hPa}$, in the MPI historical runs simulations, from 1850-51 to 2004-05. The gray lines represent individual members, and the blue line represents the ensemble mean. Here, anomalies are defined based on the 1861-1880 period.

(2012) should reassure the reader that these simulations are comparable $^{2}$ with those of the CMIP5 models. Note that the 1883-84 ensemble mean MPI anomaly in the tropical lower

\footnotetext{
${ }^{2}$ Unlike Driscoll et al. (2012), we do not detrend the time series in Fig. 5, as the stratospheric cooling is not linear over the long 1850-2005 period. Note how the cooling rate increases substan-
} 
stratosphere is close to $8^{\circ} \mathrm{C}$, with some members showing an anomaly as large $\mathrm{l}^{3}$ as $10^{\circ} \mathrm{C}$. Note, in addition, that the postKrakatau tropical warming is in this model is similar to the one for the 1991 Pinatubo eruption.

With this in mind, we now examine the forced wintertime Eurasian temperature response to the 1883 Krakatau eruption, as simulated by the MPI ensemble, obtained by averaging all 100 members. It is shown in Fig. 6a-c and, as expected, it is basically zero. We emphasize that this result is consistent with the findings of PBS19 for the 1991 Pinatubo eruption as well as with the papers cited above which have shown that there is no statistically significant volcanically forced surface winter warming in the CMIP3 and CMIP5 models. In the spirit of PBS19, and unlike most previous studies on this subject, we also examine individual ensemble members here. In Fig. 6d-f and Fig. 6h-i, we show the wintertime anomalies for the coldest and warmest member of the MPI ensemble, respectively. We emphasize that these two members are subjected to an identical volcanic aerosol forcing, which causes a very large warming in the tropical lower stratosphere in both cases (see Fig. 5). However, member no. 37 simulates a large winter cooling, whereas member no. 38 simulates a large winter warming over Eurasia. Confirming the results of PBS19, this clearly indicates that the large internal variability of the midlatitude circulation completely overwhelms any potential impact from volcanic aerosols in the stratosphere for eruptions of this magnitude.

The inability of the proposed stratospheric pathway to affect wintertime Eurasian surface temperatures in a significant way, even after a very major event such as the 1883 Krakatau eruption, is further illustrated in Fig. 7, where the zonal mean zonal wind anomalies at $60 \mathrm{~N}$ and $10 \mathrm{hPa}$ (a standard measure of the strength of the stratospheric polar vortex; see, e.g., Charlton and Polvani, 2007) are plotted against the surface temperature anomalies over the Eurasian box in the DJF months following the 1883 Krakatau eruption (one dot for each of the 100 members of the ensemble). Let us start by noting that, in the ensemble mean, the model simulates a stratospheric polar vortex acceleration of nearly $5 \mathrm{~m} \mathrm{~s}^{-1}$. This independently confirms the finding of Bittner et al. (2016a): analyzing the same ensemble using a slightly different metric, they reported that " 12 ensemble members are necessary to identify the mean polar vortex anomaly of approximately $4.5 \mathrm{~m} \mathrm{~s}^{-1}$,, when considering the Krakatau eruption alone. In other words, given a sufficiently large ensemble,

tially in the second half of the 20th century, as a consequence of ozone depletion.

${ }^{3} \mathrm{We}$ are well aware that most current-generation models are believed to overestimate the amplitude of volcanic forcing of the climate system, notably in the winter seasons. For a recent appraisal of this issue, the reader may consult Chylek et al. (2020) and references therein. It should, however, be clear to the reader that this bias - if it exists - does not invalidate the main conclusion of our study: in fact, it makes it considerably stronger. a small but statistically significant acceleration of the polar vortex forced by the Krakatau eruption can be established.

However, and this is the key point of our paper, a polar vortex acceleration of a few meters per second $\left(\mathrm{m} \mathrm{s}^{-1}\right)$ does not translate into a statistically significant Eurasian surface temperature anomaly. Bittner et al. (2016a) did not address that important point, which we make explicit here. As one can see in Fig. 7, the ensemble mean (i.e., the volcanically forced) surface temperature anomaly is tiny and actually negative but, most importantly, it is not statistically significant in this ensemble (cf. Fig. 6a-c) and it is uncorrelated with the strength of the stratospheric polar vortex $(r \sim 0.3$, implying that $90 \%$ of the surface temperature variance is not explained by the polar vortex strength). This fact corroborates the finding of PBS19 for the 1991 Pinatubo eruption: for that event models also simulate a small polar vortex acceleration in the first post-eruption winter but, again, that does not translate into a significant surface warming.

Now, one might try to argue that the MPI model analyzed here is flawed in some way, rendering it incapable of capturing the surface response to a small polar vortex acceleration. Our reply to that objection is threefold. First, the MPI model has been used extensively, for many years, to study stratosphere-troposphere dynamical coupling and the effect of volcanic eruptions on climate (e.g., Zanchettin et al., 2019; Illing et al., 2018; Timmreck et al., 2016; Bittner et al., 2016a; Bittner et al., 2016b, just to cite the most recent papers): to our knowledge, nobody has suggested a specific and demonstrable flaw that would render it inappropriate to simulate the 1883 Krakatau eruption. Second, we have separately analyzed the 1991 Pinatubo eruption in the MPI 100-member ensemble (not shown), and we found its results to be almost identical to those reported in PBS19 using different models: this suggests that there is every reason to believe that the MPI results are robust. Third, the lack of a post-Krakatau surface warming response over Eurasia is completely consistent with the many recent studies cited above showing a lack of forced Eurasia winter warming after large volcanic eruptions. Can all of these models be so uniformly wrong?

Finally, to complete the picture, we analyze 140 CMIP5 historical simulations (from 40 different models) in an attempt to determine the role (if any) of the stratospheric pathway mechanism. In order to understand Eurasian wintertime post-volcanic warming, analyses of the CMIP5 models have already been performed by several studies (e.g., Driscoll et al., 2012; Wunderlich and Mitchell, 2017): these studies have, nearly ${ }^{4}$ unanimously, reported the absence of a volcanically forced winter Eurasian warming, which is in agreement

\footnotetext{
${ }^{4}$ A single dissenting voice, Zambri and Robock (2016), concluded that the CMIP5 models show evidence for a Eurasian wintertime post-volcanic warming. However, that conclusion was reached by lowering the confidence level to $90 \%$, and the areas of significance were found to be small and did not include central Europe. Moreover, that result was obtained by averaging together the Pinatubo and Krakatau eruptions, so it is not directly comparable
} 
(a) NDJ Ens. Mean

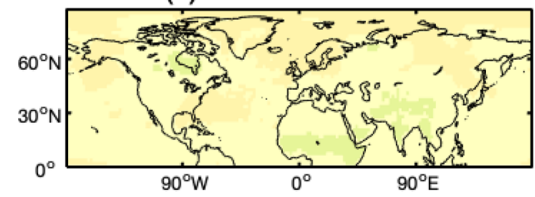

(d) NDJ \#37

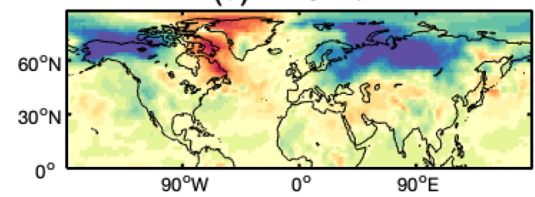

(g) NDJ \#38

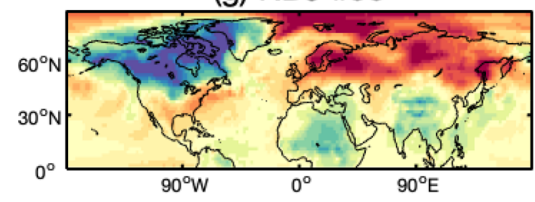

(b) DJF Ens. Mean

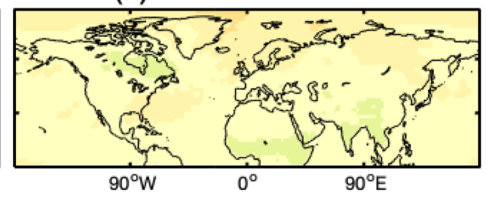

(e) DJF \#37

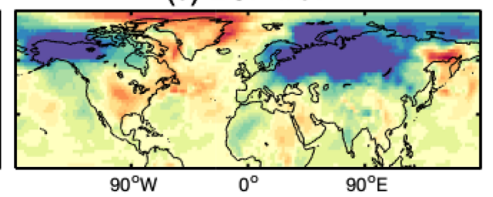

(h) DJF \#38

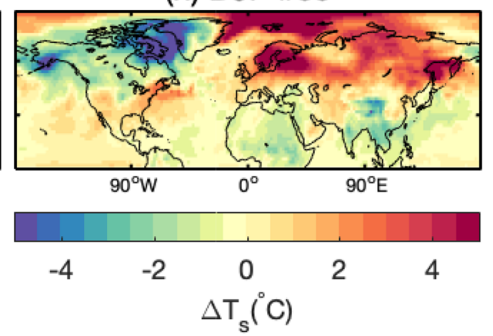

(c) JFM Ens. Mean

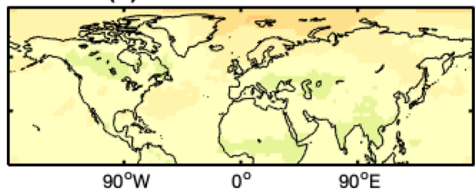

(f) JFM \#37

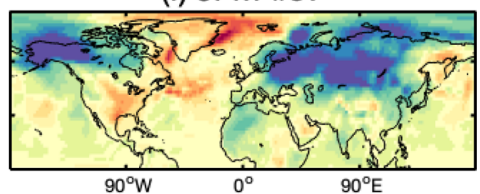

(i) JFM \#38

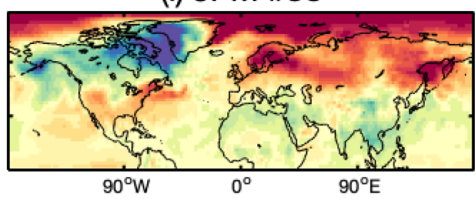

Figure 6. (a-c) MPI ensemble mean, post-Krakatau, surface temperature anomalies $\left(\Delta T_{\mathrm{S}}\right)$ averaged over (a) November to January, (b) December to February, and (c) January to March. Panels $(\mathbf{d}-\mathbf{f})$ are the same as panels $(\mathbf{a}-\mathbf{c})$ but for ensemble member no. 37. Panels $(\mathbf{g}-\mathbf{i})$ are the same as panels $(\mathbf{a}-\mathbf{c})$ but for ensemble member no. 38. Member nos. 37 and 38 simulated the respective minimum and maximum post-Krakatau Eurasian DJF anomalies across the 100-member MPI ensemble.

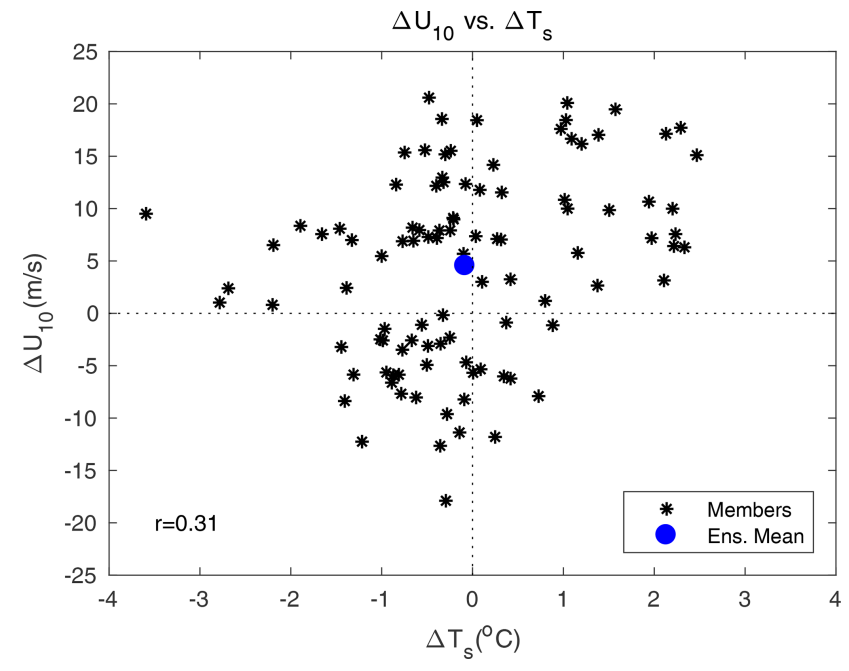

Figure 7. Post-Krakatau, DJF, zonal mean, zonal wind anomalies at $10 \mathrm{hPa}$ and $60^{\circ} \mathrm{N}\left(\Delta U_{10}\right)$ in the 100-member MPI ensemble vs. the Eurasian surface temperature anomalies $\left(\Delta T_{\mathrm{S}}\right)$. The blue dot shows the ensemble mean, and the black asterisks show individual members.

with results from the CMIP3 (Stenchikov et al., 2006) and many other single-model studies.

with the present study. Finally, we simply note that the findings of that study have not, to date, been independently reproduced.
Here, we take a different approach to examine the CMIP5 simulations: focusing exclusively on the 1883 Krakatau eruption, we separately analyze the so-called "high-top" models, which have a much better representation of the stratosphere and of its variability, and the remaining "low-top" models (see Sect. 2). One might naively expect that if the stratospheric pathway matters at all, some difference might emerge between these two group of models. As it happens, no such difference exists.

This is illustrated in Fig. 8, which compactly summarizes the findings of our study, including (1) the good agreement between observations and the 20CR reanalysis, (2) the large uncertainties in $20 \mathrm{CR}$, and (3) the nonexistent forced response in the MPI ensemble. The CMIP5 models are shown in the two left-most box-and-whisker plots, where the anomalies for the high-top and low-top models have been separately averaged: note that for both types, the multi-model mean post-Krakatau anomaly is statistically insignificant, and no obvious difference can be seen between the two types. Thus, the CMIP5 models give no ${ }^{5}$ evidence of

\footnotetext{
${ }^{5}$ Charlton-Perez et al. (2013) also explored the possible existence of post-volcanic difference between the high-top and lowtop models, although they examined a small subset of the CMIP5 models analyzed here (about half). Averaging together the first two winters following the 1991 Pinatubo and the 1982 El Chichón eruptions, they also found no difference in winter polar vortex anomalies between the mean of the high-top and of the low-top models.
} 


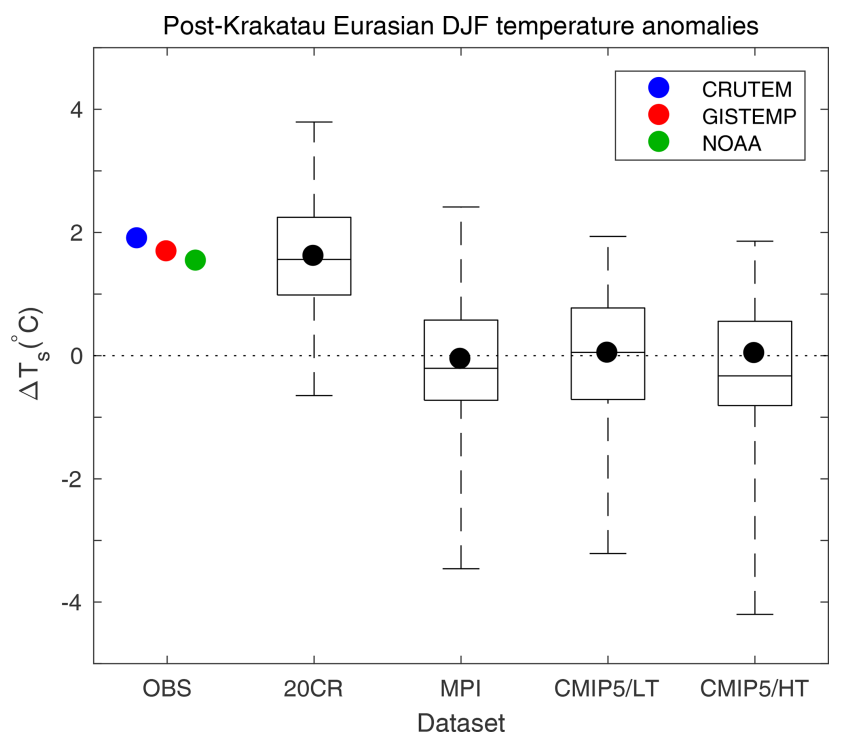

Figure 8. Eurasian surface temperature anomalies in the first postKrakatau DJF season. The colored dots show the observed values from the CRUTEM, GISTEMP, and NOAA datasets (for the latter two, a shorter three-winter reference period was used, owing to data availability). The box plots show the model values, with the median as well as the 25 th and 75 th percentiles in each dataset, the whiskers indicating the spread of the ensembles for each dataset, and the black dots indicating the mean of each ensemble. For 20CR, a 56-member ensemble was analyzed; for the MPI model, a 100member ensemble was analyzed; for the CMIP5 low-top (LT) models, 68 simulations from 21 LT models were analyzed, and for the high-top (HT) models, 62 simulations from 19 HT models were analyzed. See Table 1 for the list of CMIP5 HT and LT models as well as the respective simulations.

a stratospheric pathway playing a role in affecting Eurasian surface temperatures in the first post-Krakatau winter.

\section{Summary and discussion}

Building on a recent study of Eurasian winter temperature anomalies following the 1991 Pinatubo eruption (PBS19), we have investigated those anomalies following the 1883 Krakatau eruption, examining observational reconstructions, reanalyses, and model output (including one large ensemble and hundreds of CMIP5 simulations). Several key points have emerged from our analysis (see Fig. 8):

1. Observations indicate that from November 1883 to January 1884, Eurasian surface temperatures were warmer than in the preceding winters, with a DJF mean anomaly between 1.5 and $2{ }^{\circ} \mathrm{C}$ when averaged over the Eurasian continent. Such seasonal anomalies, however, fall in the $1 \sigma$ to $2 \sigma$ range (of the 1850 -present PDF) and are, therefore, unexceptional.
2. A 56-member ensemble of reanalyses (20CR) reveals a very large spread in post-Krakatau Eurasian wintertime surface temperatures anomalies, with a few members showing cooling. Thus, given such large uncertainties, we conclude that colder than normal post-Krakatau winter conditions are not incompatible with reanalyses.

3. The analysis of hundreds of state-of-the-art model simulations reveals the complete absence of a volcanically forced response over Eurasia in the first post-Krakatau winter. Furthermore, we find no evidence for a stratospheric pathway, which could (in theory) link tropical lower-stratosphere anomalies from volcanic aerosols to Eurasian surface temperature anomalies.

These new findings regarding the 1883 Krakatau eruption strongly corroborate the findings regarding the 1991 Pinatubo eruption, reported in PBS19. This is perhaps not surprising, as these two eruptions are of comparable magnitude. Nonetheless, we submit that it is important to document each eruption individually, as each one offers an independent observational data point. Each eruption is unique in some way: the state of the El Niño-Southern Oscillation (ENSO) and the quasi-biennial oscillation (QBO) indices, the specific location and month of the eruption, the vertical penetration of the volcanic gas and dust into the stratosphere, and the rate and extent of latitudinal spreading of the aerosol cloud are specific to each event, and these factors could affect how the eruption impacts surface temperatures ${ }^{6}$ at higher latitudes. Therefore, we believe that it is important to examine each eruption individually.

Given these potential influences, one might wonder whether the strong similarity between the results reported here for the 1883 Krakatau eruption and those reported in PBS19 for the 1992 Pinatubo eruption might stem from some environmental conditions common to both eruptions which would, in some sense, make them exceptional and, thus, nonrepresentative of most large, low-latitude eruptions. In particular, the impacts of the QBO (see, e.g., Rao et al., 2020) and of ENSO (see, e.g., Calvo et al., 2008) on the polar stratosphere are well documented and have been studied in some detail in the context of the Pinatubo eruption (Thomas et al., 2009b,a). As for the QBO, while it is well known that the QBO was in an easterly phase in the first winter following the Pinatubo eruption (see, e.g., Toohey et al., 2014 and the discussion therein), no data are available as to the QBO state in the winter of 1883-84. As for ENSO, the first post-Pinatubo

\footnotetext{
${ }^{6}$ For instance, the 1902 eruption of Santa Maria was also a powerful $(\mathrm{VEI}=6)$ low-latitude event, but the volcanic stratospheric sulfur injection (VSSI) from that eruption was only a fraction of the Pinatubo and Krakatau values (Toohey and Sigl, 2017), with the expectation of a comparably smaller impact at high latitudes. In contrast, the 1883 Krakatau eruption stands together with the 1991 Pinatubo eruption as the only other recent, large $(\mathrm{VEI}=6)$, low-latitude, eruption with considerable stratospheric sulfur injection (for both, VSSI $\sim 9 \mathrm{Tg}[\mathrm{S}]$ ).
} 
winter occurred during an El Niño event, whereas ENSO was in a neutral state in the first post-Krakatau winter. Finally, to the best of our knowledge, no study has advocated that these two eruptions are peculiar in any particular way and should, thus, be discarded as nonrepresentative.

Therefore, we now ask the following question: how do the findings reported above for Krakatau, taken together with the findings reported in PBS19 for Pinatubo, reshape our understanding of whether large, low-latitude eruptions can cause a winter warming over Eurasia? First, it is interesting to note that an anomalous warming was indeed observed following both eruptions. However, as we have shown here, those anomalies $\left(\sim 1-2{ }^{\circ} \mathrm{C}\right.$ in DJF) are far from exceptional. Second, the analysis of a wealth of state-of-the-art model simulations leaves no doubt that for $\mathrm{VEI}=6$ eruptions - such as Krakatau and Pinatubo - there is no statistically significant forced Eurasian surface winter warming in climate models. This is despite the fact that most models considerably overestimate $^{7}$ the lower stratospheric tropical warming that follows these eruptions. Third, we stress that the stratospheric pathway fails to produce a significant Eurasian warming not because it is physically implausible, but because the amplitude of the polar vortex acceleration that accompanies the warming of the lower-stratospheric by volcanic aerosols (a few meters per second, for both Pinatubo and Krakatau) is simply insufficient to overcome the very large internal variability of the midlatitude circulation.

We submit that, at this point, the evidence is overwhelming: low-latitude eruptions as large as Pinatubo or Krakatau are unable to cause a forced surface temperature anomaly over Eurasia that can be distinguished from unforced variability. As explained in detail in PBS19 (we refer to reader to Sect. 5, specifically), the early claims of a causal connection were based on low-resolution models with poor stratospheric resolution and little stratospheric variability as well as on a few observational studies which often commingled high- and low-latitude eruptions as well as the first and second posteruption winters (we note that none of these observational studies were independently validated). Therefore, the situation is now reversed: rather than taking for granted that large, low-latitude eruptions cause Eurasian winter warming (and seeking to explain the lack of causal evidence in models as, e.g., in Driscoll et al., 2012), the onus has now shifted to presenting evidence in support of the claim that a causal connection exists at all.

Where might one look for that evidence? If there is any hope left for the stratospheric pathway mechanism to communicate the impact of low-latitude eruptions to Eurasia in winter, we need to look at larger eruptions. A few of those are well known, and the next best candidate might be the

\footnotetext{
${ }^{7}$ In the case of Pinatubo, observations indicate a lower stratospheric warming of the order of $2.5^{\circ} \mathrm{C}$ (Labitzke and McCormick, 1992; Free and Lanzante, 2009), whereas models often show anomalies of the order of 6 to $8^{\circ} \mathrm{C}$, as seen, e.g., in Fig. 5 .
}

1815 Tambora eruption. Note, however, that its VSSI index is only 3 times larger than Krakatau and Pinatubo (Toohey and Sigl, 2017), so even that event may not be large enough. One might then be tempted to look further back in time, e.g., at the 1257 Samalas eruption. Doing so, however, raises additional questions. Perhaps the most troublesome is the following: dendrochronological records constitute the bulk of proxy observations used to produce temperature reconstructions, and those are mostly found in summer (the growing season). As a consequence, the robustness of winter reconstructions remains unclear (Steiger et al., 2018, for instance, show that the DJF skill scores in their reconstruction are much weaker than for the other seasons). However, the stratospheric pathway is fundamentally a winter mechanism, as it requires the presence of the stratospheric polar vortex (which disappears in the summer months). Hence, annual-mean temperatures, which are typical of many, perhaps most, reconstructions (e.g., the recent Last Millennium Climate Reanalysis project; Hakim et al., 2016) are fundamentally inadequate for the task.

All things considered, establishing the existence of a volcanically forced winter warming over Eurasia, as well as of an accompanying stratospheric pathway (if any), appears to be a truly daunting challenge.

Code and data availability. All code and data can be made available upon reasonable request.

Author contributions. LMP originally conceived the study and designed it with SJC. SJC performed the analysis and produced the figures. LMP wrote the paper in close consultation with SJC. Both authors contributed to the interpretation of the results.

Competing interests. The authors declare that they have no conflict of interest.

Acknowledgements. Lorenzo M. Polvani is grateful to Alexandro Tejedor-Vargas for several enlightening conversations, Matthew Toohey for a thoughtful review, and Alan Robock for many friendly discussions and for unsolicited, yet very helpful, comments on an earlier version of the paper.

Financial support. This research has been supported by the US National Science Foundation, Directorate for Geosciences (grant no. 1914569).

Review statement. This paper was edited by Mathias Palm and reviewed by Matthew Toohey and one anonymous referee. 


\section{References}

Bittner, M.: On the discrepancy between observed and simulated dynamical responses of Northern Hemisphere winter climate to large tropical volcanic eruptions, $\mathrm{PhD}$ thesis, Univerisity of Hamburg, Reports on Earth System Science, no. 173, 2015.

Bittner, M., Schmidt, H., Timmreck, C., and Sienz, F.: Using a large ensemble of simulations to assess the Northern Hemisphere stratospheric dynamical response to tropical volcanic eruptions and its uncertainty, Geophys. Res. Lett., 43, 93249332, https://doi.org/10.1002/2016GL070587, 2016a.

Bittner, M., Timmreck, C., Schmidt, H., Toohey, M., and Krüger, K.: The impact of wave-mean flow interaction on the Northern Hemisphere polar vortex after tropical volcanic eruptions, J. Geophys. Res.-Atmos., 121, 5281-5297, https://doi.org/10.1002/2015JD024603, 2016b.

Butler, A. H., Charlton-Perez, A., Domeisen, D. I., Simpson, I. R., and Sjoberg, J.: Predictability of Northern Hemisphere final stratospheric warmings and their surface impacts, Geophys. Res. Lett., 46, 10578-10588, https://doi.org/10.1029/2019GL083346, 2019.

Calvo, N., García-Herrera, R., and Garcia, R. R.: The ENSO signal in the stratosphere, Ann. NY. Acad. Sci., 1146, 16-31, 2008.

Charlton, A. J. and Polvani, L. M.: A new look at stratospheric sudden warmings. Part I: Climatology and modeling benchmarks, J. Climate, 20, 449-469, https://doi.org/10.1175/JCLI3996.1, 2007.

Charlton-Perez, A. J., Baldwin, M. P., Birner, T., Black, R. X., Butler, A. H., Calvo, N., Davis, N. A., Gerber, E. P., Gillett, N., Hardiman, S., Kim, J., Krüger, K., Lee, Y., Manzini, E., McDaniel, B. A., Polvani, L., Reichler, T., Shaw, T. A., Sigmond, M., Son, S., Toohey, M., Wilcox, L., Yoden, S., Christiansen, B., Lott, F., Shindell, D., Yukimoto, S., and Watanabe, S.: On the lack of stratospheric dynamical variability in lowtop versions of the CMIP5 models, J. Geophys. Res., 118, 24942505, https://doi.org/10.1002/jgrd.50125, 2013.

Chylek, P., Folland, C., Klett, J. D., and Dubey, M. K.: CMIP5 climate models overestimate cooling by volcanic aerosols, Geophys. Res. Lett., 47, e2020GL087047, https://doi.org/10.1029/2020GL087047, 2020.

Compo, G. P., Whitaker, J. S., and Sardeshmukh, P. D.: Feasibility of a 100 year reanalysis using only surface pressure data, B. Am. Meteorol. Soc., 87, 175-190, https://doi.org/10.1175/BAMS-872-175, 2006.

Compo, G. P., Whitaker, J. S., Sardeshmukh, P., Matsui, N., Allan, R., Gleason, X. Y. B., Vose, R., Rutledge, G., Bessemoulin, P., Broennimann, S., Brunet, M., Crouthamel, R., Grant, A., Groisman, P., Jones, P., Kruk, M., Kruger, A., Marshall, G., Maugeri, M., Mok, H., Nordli, O., Ross, T., Trigo, R., Wang, X., Woodruff, S., and Worley, S.: The Twentieth Century Reanalysis Project, Q. J. Roy. Meteor. Soc., 137, 1-128, https://doi.org/10.1002/qj.776, 2011.

Deser, C., Lehner, F., Rodgers, K., Ault, T., Delworth, T., DiNezio, P., Fiore, A., Frankignoul, C., Fyfe, J., Horton, D., Kay, J., Knutti, R., Lovenduski, N., Marotzke, J., McKinnon, K. A., Minobe, S., Randerson, J., Screen, J., Simpson, I., and Ting, M.: Insights from Earth system model initial-condition large ensembles and future prospects, Nat. Geosci., 40, 277-286, https://doi.org/10.1038/s41558-020-0731-2, 2020.
Driscoll, S., Bozzo, A., Gray, L. J., Robock, A., and Stenchikov, G.: Coupled Model Intercomparison Project 5 (CMIP5) simulations of climate following volcanic eruptions, J. Geophys. Res., 117, D17105, https://doi.org/10.1029/2012JD017607, 2012.

Fischer, E. M., Luterbacher, J., Zorita, E., Tett, S., Casty, C., and Wanner, H.: European climate response to tropical volcanic eruptions over the last half millennium, Geophys. Res. Lett., 34, L05707, https://doi.org/10.1029/2006GL027992, 2007.

Free, M. and Lanzante, J.: Effect of volcanic eruptions on the vertical temperature profile in radiosonde data and climate models, J. Climate, 22, 2925-2939, https://doi.org/10.1175/2008JCLI2562.1, 2009.

Fyfe, J. C.: Southern Ocean warming due to human influence, Geophys. Res. Lett., 33, L19701, https://doi.org/10.1029/2006GL027247, 2006.

Gleckler, P., AchutaRao, K., Gregory, J., Santer, B., Taylor, K., and Wigley, T.: Krakatoa lives: The effect of volcanic eruptions on ocean heat content and thermal expansion, Geophys. Res. Lett., 33, L17702, https://doi.org/10.1029/2006GL026771, 2006.

Graf, H., Kirchner, I., Robock, A., and Schult, I.: Pinatubo eruption winter climate effects: Model versus observations, Clim. Dynam., 9, 81-93, https://doi.org/10.1007/BF00210011, 1993.

Groisman, P. Y.: Possible regional climate consequences of the Pinatubo eruption: An empirical approach, Geophys. Res. Lett., 19, 1603-1606, https://doi.org/10.1029/92GL01474, 1992.

Hakim, G. J., Emile-Geay, J., Steig, E. J., Noone, D., Anderson, D. M., Tardif, R., Steiger, N., and Perkins, W. A.: The last millennium climate reanalysis project: Framework and first results, J. Geophys. Res.-Atmos., 121, 6745-6764, https://doi.org/10.1002/2016JD024751, 2016.

Illing, S., Kadow, C., Pohlmann, H., and Timmreck, C.: Assessing the impact of a future volcanic eruption on decadal predictions, Earth Syst. Dynam., 9, 701-715, https://doi.org/10.5194/esd-9701-2018, 2018.

Jones, P. D., Lister, D. H., Osborn, T. J., Harpham, C., Salmon, M., and Morice, C. P.: Hemispheric and large-scale land surface air temperature variations: an extensive revision and an update to 2010, J. Geophys. Res., 117, D05127, https://doi.org/10.1029/2011JD017139, 2012.

Kay, J. E., Deser, C., Phillips, A., Mai, A., Hannay, C., Strand, G., Arblaster, J. M., Bates, S. C., Danabasoglu, G., Edwards, J., Holland, M., Kushner, P., Lamarque, J.-F., Lawrence, D., Lindsay, K., Middleton, A., Munoz, E., Neale, R., Oleson, K., Polvani, L., and Vertenstein, M.: The Community Earth System Model (CESM) Large Ensemble Project: A community resource for studying climate change in the presence of internal climate variability, B. Am. Meteorol. Soc., 96, 1333-1349, https://doi.org/10.1175/JCLI-D-11-00015.1, 2015.

Kirchner, I., Stenchikov, G. L., Graf, H.-F., Robock, A., and Antuña, J. C.: Climate model simulation of winter warming and summer cooling following the 1991 Mount Pinatubo volcanic eruption, J. Geophys. Res.-Atmos., 104, 19039-19055, https://doi.org/10.1029/1999JD900213, 1999.

Kobayashi, S., Ota, Y., Harada, Y., Ebita, A., Moriya, M., Onoda, H., Onogi, K., Kamahori, H., Kobayashi, C., Endo, H., Miyaoka, K., and Takahashi, K.: The JRA-55 Reanalysis: General Specifications and Basic Characteristics, J. Meteorol. Soc. Jpn. Ser. II, 93, 5-48, https://doi.org/10.2151/jmsj.2015-001, 2015. 
Kodera, K.: Influence of volcanic eruptions on the troposphere through stratospheric dynamical processes in the northern hemisphere winter, J. Geophys. Res.-Atmos., 99, 1273-1282, https://doi.org/10.1029/93JD02731, 1994.

Labitzke, K. and McCormick, M.: Stratospheric temperature increases due to Pinatubo aerosols, Geophys. Res. Lett., 19, $207-$ 210, https://doi.org/10.1029/91GL02940, 1992.

Lenssen, N., Schmidt, G., Hansen, J., Menne, M., Persin, A., Ruedy, R., and Zyss, D.: Improvements in the GISTEMP uncertainty model, J. Geophys. Res.-Atmos., 124, 6307-6326, https://doi.org/10.1029/2018JD029522, 2019.

Maher, N., Milinski, S., Suarez-Gutierrez, L., Botzet, M., Dobrynin, M., Kornblue, L., Kröger, J., Takano, Y., Ghosh, R., Hedemann, C., Li, C., Li, H., Manzini, E., Notz, N., Putrasahan, D., Boysen, L., Claussen, M., Ilyina, T., Olonscheck, D., Raddatz, T., Stevens, B., and Marotzke, J.: The Max Planck Institute Grand Ensemble: Enabling the Exploration of Climate System Variability, J. Adv. Model. Earth. Sy., 11, 1-21, https://doi.org/10.1029/2019MS001639, 2019.

Perlwitz, J. and Graf, H.-F.: The statistical connection between tropospheric and stratospheric circulation of the Northern Hemisphere in winter, J. Climate, $\quad 8, \quad 2281-2295$, https://doi.org/10.1175/15200442(1995)008<2281:TSCBTA>2.0.CO;2, 1995.

Poli, P., Hersbach, H., Dee, D. P., Berrisford, P., Simmons, A. J., Vitart, F., Laloyaux, P., Tan, D. G., Peubey, C., Thépaut, J.-N., et al.: ERA-20C: An atmospheric reanalysis of the twentieth century, J. Climate, 29, 4083-4097, https://doi.org/10.1175/JCLI-D15-0556.1, 2016.

Polvani, L. M., Banerjee, A., and Schmidt, A.: Northern Hemisphere continental winter warming following the $1991 \mathrm{Mt}$. Pinatubo eruption: reconciling models and observations, Atmos. Chem. Phys., 19, 6351-6366, https://doi.org/10.5194/acp19-6351-2019, 2019.

Rao, J., Garfinkel, C. I., and White, I. P.: Impact of the QuasiBiennial Oscillation on the Northern Winter Stratospheric Polar Vortex in CMIP5/6 Models, J. Climate, 33, 4787-4813, 2020.

Rayner, N., Parker, D. E., Horton, E., Folland, C. K., Alexander, L. V., Rowell, D., Kent, E., and Kaplan, A.: Global analyses of sea surface temperature, sea ice, and night marine air temperature since the late nineteenth century, J. Geophys. Res.-Atmos., 108, 4407, https://doi.org/10.1029/2002JD002670, 2003.

Rea, G., Riccio, A., Fierli, F., Cairo, F., and Cagnazzo, C.: Stratosphere-resolving CMIP5 models simulate different changes in the Southern Hemisphere, Clim. Dynam., 50, 2239-2255, https://doi.org/10.1007/s00382-017-3746-2, 2018.

Robock, A.: El Chinchón eruption: The dust cloud of the century, Nature, 301, 373, https://doi.org/10.1038/301373a0, 1983.

Robock, A.: Volcanic eruptions and climate, Rev. Geophys., 38, 191-219, https://doi.org/10.1029/1998RG000054, 2000.

Robock, A. and Mao, J.: Winter warming from large volcanic eruptions, Geophys. Res. Lett., 19, 2405-2408, https://doi.org/10.1029/92GL02627, 1992.

Robock, A. and Mao, J.: The volcanic signal in surface temperature observations, J. Climate, $8, \quad 1086-1103$, https://doi.org/10.1175/15200442(1995)008<1086:TVSIST>2.0.CO;2, 1995.

Shindell, D. T., Schmidt, G. A., Mann, M. E., and Faluvegi, G.: Dynamic winter climate response to large tropical volcanic eruptions since 1600, J. Geophys. Res.-Atmos., 109, D05104, https://doi.org/10.1029/2003JD004151, 2004.

Simkin, T. and Fiske, R.: Krakatau, 1883: the volcanic eruption and its effects, Smithsonian Institution Press, Washington, D.C., 1983.

Smith, T. M., Reynolds, R. W., Peterson, T. C., and Lawrimore, J.: Improvements to NOAA's historical merged land - ocean surface temperature analysis (1880-2006), J. Climate, 21, 2283-2296, https://doi.org/10.1175/2007JCLI2100.1, 2008.

Steiger, N. J., Smerdon, J. E., Cook, E. R., and Cook, B. I.: A reconstruction of global hydroclimate and dynamical variables over the Common Era, Sci. Data, 5, 180086, https://doi.org/10.1038/sdata.2018.86, 2018.

Stenchikov, G., Hamilton, K., Stouffer, R. J., Robock, A., Ramaswamy, V., Santer, B., and Graf, H.-F.: Arctic Oscillation response to volcanic eruptions in the IPCC AR4 climate models, J. Geophys. Res.-Atmos., 111, D07107, https://doi.org/10.1029/2005JD006286, 2006.

Taylor, K. E., Stouffer, R. J., and Meehl, G. A.: An overview of CMIP5 and the experiment design, B. Amer. Meteorol. Soc., 93, 485-498, https://doi.org/10.1175/BAMS-D-11-00094.1, 2012.

Thomas, M. A., Giorgetta, M. A., Timmreck, C., Graf, H.-F., and Stenchikov, G.: Simulation of the climate impact of Mt. Pinatubo eruption using ECHAM5 - Part 2: Sensitivity to the phase of the QBO and ENSO, Atmos. Chem. Phys., 9, 3001-3009, https://doi.org/10.5194/acp-9-3001-2009, 2009a.

Thomas, M. A., Timmreck, C., Giorgetta, M. A., Graf, H.-F., and Stenchikov, G.: Simulation of the climate impact of Mt. Pinatubo eruption using ECHAM5 - Part 1: Sensitivity to the modes of atmospheric circulation and boundary conditions, Atmos. Chem. Phys., 9, 757-769, https://doi.org/10.5194/acp-9757-2009, 2009 b.

Timmreck, C., Pohlmann, H., Illing, S., and Kadow, C.: The impact of stratospheric volcanic aerosol on decadalscale climate predictions, Geophys. Res. Lett., 43, 834-842, https://doi.org/10.1002/2015GL067431, 2016.

Toohey, M. and Sigl, M.: Volcanic stratospheric sulfur injections and aerosol optical depth from 500 BCE to 1900 CE, Earth Syst. Sci. Data, 9, 809-831, https://doi.org/10.5194/essd-9-809-2017, 2017.

Toohey, M., Krüger, K., Bittner, M., Timmreck, C., and Schmidt, H.: The impact of volcanic aerosol on the Northern Hemisphere stratospheric polar vortex: mechanisms and sensitivity to forcing structure, Atmos. Chem. Phys., 14, 13063-13079, https://doi.org/10.5194/acp-14-13063-2014, 2014.

Vose, R. S., Arndt, D., Banzon, V. F., Easterling, D. R., Gleason, B., Huang, B., Lawrimore, J. H., Menne, M. J., Peterson, T. C., Reynolds, R. W., Smith, T. M., Jr., C. N. W., and Wuertz, D. L.: NOAA's merged land-ocean surface temperature analysis, B. Am. Meteorol. Soc., 21, 2283-2296, https://doi.org/10.1175/BAMS-D-11-00241.1, 2012.

Wunderlich, F. and Mitchell, D. M.: Revisiting the observed surface climate response to large volcanic eruptions, Atmos. Chem. Phys., 17, 485-499, https://doi.org/10.5194/acp-17-485-2017, 2017.

Zambri, B. and Robock, A.: Winter warming and summer monsoon reduction after volcanic eruptions in Coupled Model Intercomparison Project 5 (CMIP5) simulations, Geophys. Res. Lett., 43, 10920-10928, https://doi.org/10.1002/2016GL070460, 2016. 
Zanchettin, D., Timmreck, C., Toohey, M., Jungclaus, J. H., Bittner, M., Lorenz, S. J., and Rubino, A.: Clarifying the relative role of forcing uncertainties and initialcondition unknowns in spreading the climate response to volcanic eruptions, Geophys. Res. Lett., 46, 1602-1611, https://doi.org/10.1029/2018GL081018, 2019. 